\title{
The distribution profiles of very low density and low density lipoproteins in poorly-controlled male, Type 2 (non-insulin-dependent) diabetic patients
}

\author{
R. W. James and D.Pometta \\ Division de Diabétologie, Département de Médecine, Hôpital Cantonal Universitaire, Geneva, Switzerland
}

\begin{abstract}
Summary. The distribution and composition of lipoproteins spanning the very low density and low density lipoprotein spectra have been analysed in ten poorly-controlled, male, Type 2 (non-insulin-dependent), diabetic patients pre-disposed to mild, secondary hypertriglyceridaemia. As compared to age-matched control subjects, the diabetic patients displayed grossly modified, distinctly atherogenic lipoprotein profiles. Modifications were not limited to the very low density lipoprotein profile, as would be expected from the pre-treatment hypertriglyceridaemia. There was also an aberrant low density lipoprotein profile, which was not evident from plasma cholesterol measurements, especially as the diabetic patients at entry were well matched to control subjects with respect to plasma levels of this lipid. Compositional abnormalities were also observed in the poorly-con-
\end{abstract}

trolled diabetic group, although these were less marked than the distributional changes. There were substantial improvements of the abnormalities detailed above, even over a short treatment period (two weeks), with therapy designed primarily to ameliorate metabolic control. The data suggest that, in the presence of poor metabolic control and hypertriglyceridaemia, occult, atherogenic modifications of low density lipoproteins can occur. The results argue in favour of strict control of triglyceride levels even in diabetic patients with apparently acceptable cholesterol levels.

Key words: Type 2 (non-insulin-dependent) diabetes mellitus, atherosclerosis, very low density lipoproteins, low density lipoproteins, glycaemic control, triglycerides, cholesterol.
Hypertriglyceridaemia is the most frequently encountered lipid disorder in poorly-controlled Type 2 (non-insulin-dependent) diabetic patients [1-3]. Raised triglyceride levels reflect increased plasma concentrations of very low density lipoproteins (VLDL). The latter are precursors of low density lipoproteins (LDL; [4, 5]) and also have close metabolic links with high density lipoproteins (HDL; [6, 7]). Whereas LDL and HDL are established, major atherosclerotic risk factors, there still remains considerable uncertainty as to the risk status of triglycerides/VLDL. This derives primarily from the inability of epidemiological studies to consistently depict triglycerides as independent risk factors for cardiovascular disease [8]. Undoubtedly, the close metabolic ties mentioned above contribute to this uncertainty. However, recent reappraisals of the potential role of triglycerides have generally favoured attribution of a high risk status $[8,9]$. Obviously, it has important implications for diabetic patients.

Hypertriglyceridaemia is an umbrella term covering a variety of metabolic disorders which affect VLDL levels and influence the atherosclerotic process to varying de- grees $[8,10]$. This heterogeneity greatly hinders a true appreciation of the role of triglycerides in cardiovascular disease. In this respect, detailed information on the structural and metabolic diversity of VLDL should help to clarify the situation. Such studies in the non-diabetic population have substantially contributed to an understanding of the inherent heterogeneity of VLDL [11-13]. Comparable data from diabetic populations are generally lacking. Thus, the primary aim of this study was to examine VLDL and LDL subfraction composition and distribution in poorly-controlled Type 2 diabetic patients with mild, secondary hypertriglyceridaemia. These lipid parameters were subsequently re-examined after short-term treatment designed to improve glycaemic control.

\section{Subjects and methods}

Type 2 diabetic patients were recruited from those referred to the Diabetes Teaching Unit at the Cantonal Hospital in Geneva. Ten poorly-controlled male patients with secondary hypertriglyceridaemia entered the study. Fasting blood samples were obtained at 
entry and after a short, two-week period of hospitalisation where emphasis was placed on improving glycaemic control. Various clinical parameters are given in Table 1 . The average duration of diabetes was $6.1 \pm 4.5$ years. No patient was receiving lipid lowering drugs; two patients were receiving antihypertensive medication (a calcium antagonist and $\beta$-blocker/diuretic) and this was continued during their hospitalisation. Prior to entry, one patient was treated by diet alone, seven with oral anti-diabetic drugs (five with sulphonylureas, two with biguanides) and two with insulin. During hospitalisation, the diet-treated patient received oral anti-diabetic medication whilst three additional patients also received insulin. Daily caloric intake at entry and during hospitalisation was $2225 \pm 590 \mathrm{kcals}$ and $1612 \pm 216$ kcals, respectively $(p=0.065)$. Diet was modified from an average fat:protein:carbohydrate composition (\%) at entry of $40.5 \pm 1.9: 19.0 \pm 3.8: 39.9 \pm 6.2$ to one of standard composition (30:20:50). Four patients showed no weight change during this period, one gained weight $(0.4 \mathrm{~kg})$ and five showed weight losses of $0.5-3.3 \mathrm{~kg}$ (average $1.6 \mathrm{~kg}$ ).

Age-matched control subjects were recruited from the personnel of the University Hospital in Geneva. Their clinical characteristics are given in Table 1 .

\section{Lipoprotein fractionation}

Fasting plasma samples were fractionated by cumulative flotation ultracentrifugation [14] as described previously [15]. It gives rise to three subfractions of VLDL (VLDL-1, Sf >100; VLDL-2, Sf 60 100; VLDL-3, Sf 20-60) and LDL (LDL-1, Sf 12-20; LDL-2, Sf 6-12; LDL-3, Sf 3-6). VLDL subfractions were isolated from $2 \times 2.0 \mathrm{ml}$ of plasma; LDL subfractions were isolated from the equivalent of $2.0 \mathrm{ml}$ of plasma after removal of VLDL $(16 \mathrm{~h}, 40000 \mathrm{rev} / \mathrm{min}$, Kontron 45.6 rotor).

HDL-cholesterol was measured after precipitation of lower density lipoproteins from whole plasma with phosphotungstate [16].

\section{Lipid and protein analyses}

Lipids were quantified with commercially available enzyme assays, as described previously $[15,16]$. Quality control of lipid measurements is assured by the Prague reference centre of the WHO. Typical within-day and between-day coefficients of variation are 0.8 and 1.2 for cholesterol; 1.3 and 2.6 for triglycerides. Esterified cholesterol

Table 1. Clinical parameters of the control group and diabetic patients before and after treatment

\begin{tabular}{lccc}
\hline Parameter & \multicolumn{2}{l}{ Diabetic patients } & Control \\
\cline { 2 - 3 } & Before & After & \\
\hline Age (years) & $54.3 \pm 8.6$ & - & $54.2 \pm 7.9$ \\
BMI (kg/m ${ }^{2}$ ) & $30.1 \pm 2.7$ & - & $23.3 \pm 2.0^{\mathrm{a}}$ \\
Fasting plasma glucose (mmol/1) & $12.1 \pm 3.4$ & $6.6 \pm 0.9^{\mathrm{a}}$ & $4.1 \pm 1.1^{\mathrm{a}, \mathrm{d}}$ \\
Glycaemic profile (mmol/l) & $12.3 \pm 3.8$ & $7.1 \pm 1.5^{\mathrm{a}}$ & - \\
Glucosuria (g/24h) & $38.0 \pm 33.8$ & $1.4 \pm 3.0^{\mathrm{b}}$ & - \\
HbA $1 \mathrm{c}(\%)$ & $9.8 \pm 1.4$ & - & - \\
Proteinuria (g/24 h) & $0.19 \pm 0.35$ & - & - \\
Creatinine ( $\mu$ mol/l) & $100.1 \pm 19.4$ & - & - \\
Plasma chol. (mmol/l) & $5.99 \pm 0.83$ & $5.13 \pm 0.86^{\mathrm{b}}$ & $5.88 \pm 0.75$ \\
Plasma triglycerides (mmol/l) & $3.09 \pm 0.87$ & $1.69 \pm 0.5^{\mathrm{a}}$ & $1.05 \pm 0.32^{\mathrm{a}, \mathrm{e}}$ \\
HDL-chol. (mmol/l) & $0.86 \pm 0.10$ & $0.84 \pm 0.14$ & $1.35 \pm 0.34^{\mathrm{a}}$ \\
Apo A-I (mg/dl) & $146.7 \pm 26.9$ & $127.1 \pm 24.4^{\mathrm{c}}$ & $168.9 \pm 3.5^{\mathrm{e}}$ \\
Apo B (mg/dl) & $145.2 \pm 19.1$ & $119.2 \pm 13.2^{\mathrm{c}}$ & $136.1 \pm 38.7$ \\
\hline
\end{tabular}

Values are expressed \pm SD. Fasting plasma glucose and lipid levels were measured at 08.00 hours. The glycaemic profile is the average value for measurements made at $08.00,11.00$ and 17.00 hours. Before, at entry; after, following treatment

${ }^{\mathrm{a}} p<0.001$; ${ }^{\mathrm{b}} p<0.005 ;{ }^{\mathrm{c}} p<0.05$ vs diabetic patients at entry;

d $p<0.001 ;{ }^{\mathrm{e}} p<0.005$ vs diabetic patients after treatment was estimated as $(($ total cholesterol $)-($ free cholesterol $)) \times 1.68$. The total protein content of the subfractions was measured by the procedure of Lowry et al. [17], as was protein in the precipitate (apolipoprotein (apo) B) and the infranatant (essentially apos C and $E$ as revealed by SDS-PAGE) resulting from tetramethyl urea treatment of the subfractions $[15,18]$. [16].

Plasma apo A-I and B were quantified by electroimmunoassay

\section{Other measurements}

Haemoglobin $\mathrm{A}_{1 \mathrm{c}}$ and plasma glucose were measured as described previously [19].

\section{Statistical analysis}

Comparisons were made using the unpaired (diabetic patients vs control subjects) or paired (between diabetic patients) Student's $t$-test.

\section{Results}

\section{Plasma lipid and apolipoprotein levels}

As shown in Table 1, diabetic patients at entry were well matched to control subjects with respect to age, plasma cholesterol and apo B levels. HDL-cholesterol levels were significantly lower, as was apo A-I (although it did not reach significance at $p \leq 0.05$ ). There were also highly significant differences in plasma triglyceride levels and BMI. Subsequent to treatment, there were significant improvements in parameters of metabolic control, notably fasting plasma glucose, the daily glycaemic profile and glucosuria (Table 1). There were also significant reductions in plasma levels of cholesterol, triglycerides and apo B. HDL-cholesterol levels were not modified, but there was a significant decrease in plasma concentrations of apo A-I.

\section{Plasma lipoprotein concentrations}

Plasma concentrations of apo B containing lipoproteins (VLDL + LDL) were significantly increased in pre-treatment diabetic patients (Fig. 1 a). It was due essentially to VLDL, LDL levels being similar to control values. Treatment was accompanied by significant reductions in VLDL, although they still remained above control values. There were no significant differences in plasma levels of total LDL between diabetic and control groups.

The differences in total VLDL concentrations noted above reflected those of individual lipid and total protein components of the lipoproteins. All were significantly increased in pre-treatment diabetic subjects, with respect both to post-treatment and control values. Treatment significantly reduced, but did not normalise their plasma concentrations. The values for total cholesterol are given as an example in Figure $1 \mathrm{~b}$. 


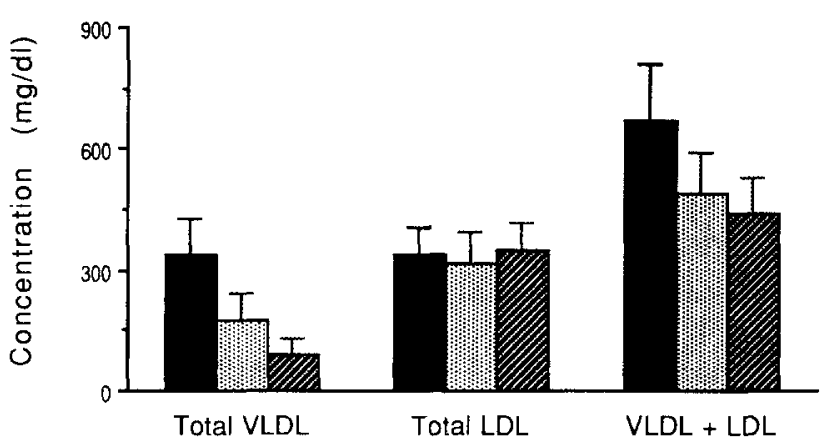

a Lipoprotein subfraction

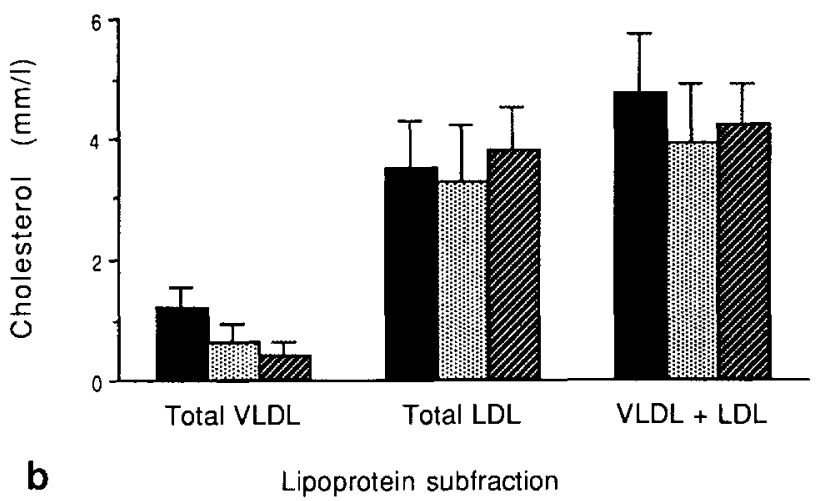

Fig. 1 a,b. Total VLDL $(\delta<1.006 \mathrm{~g} / \mathrm{ml})$ and total LDL $(\delta 1.006-$ $1.063 \mathrm{~g} / \mathrm{ml}$ ) were isolated from fasting plasma by sequential ultracentrifugation. a Total plasma concentration was computed as the sum of the concentrations of the individual lipid and total protein components. b Total cholesterol concentrations of the subfractions. Statistical analyses: pre-treatment VLDL vs control VLDL, $p<0.001$ for $\mathbf{a}$ and $\mathbf{b}$; post-treatment VLDL vs control VLDL, $p<0.005$ for $\mathbf{a}$ and $p<0.05$ for $\mathbf{b}$. There were no statistically significant differences for the LDL samples. - Pre-treatment; posttreatment; control

\section{VLDL subfractions}

As shown in Figure $2 \mathrm{a}$, there were highly significant increases in the plasma concentrations of each VLDL subfraction. These were more marked for VLDL-1 and 2 (five-fold increase compared to control values) than VLDL-3 (two-fold increase). All responded favourably to treatment, particularly VLDL-1 and 2 (Fig. 2a), with substantial reductions in their plasma concentrations which still, however, remained above control levels.

The global increases noted above represented those of the individual lipid and total protein components of the subfractions. All components were significantly higher in each VLDL subfraction from pre-treatment diabetic patients, as compared to control subjects, and all responded favourably to treatment (Table 2).

The relative compositions of the VLDL subfractions are given in Table 3. With respect to pre-treatment and control samples, there appeared to be a divergence between VLDL-1 and 2 subfractions and VLDL-3. That is, diabetic VLDL-1 and 2 appeared to be enriched in phospholipids, free and esterified cholesterol and depleted in

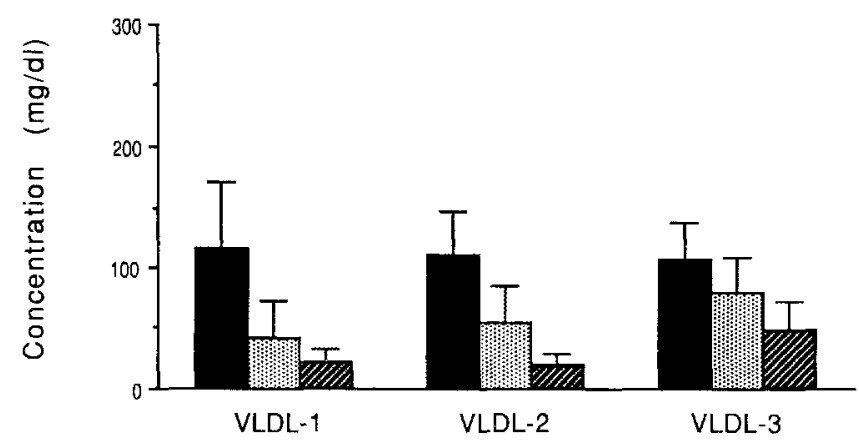

a

Lipoprotein subfraction

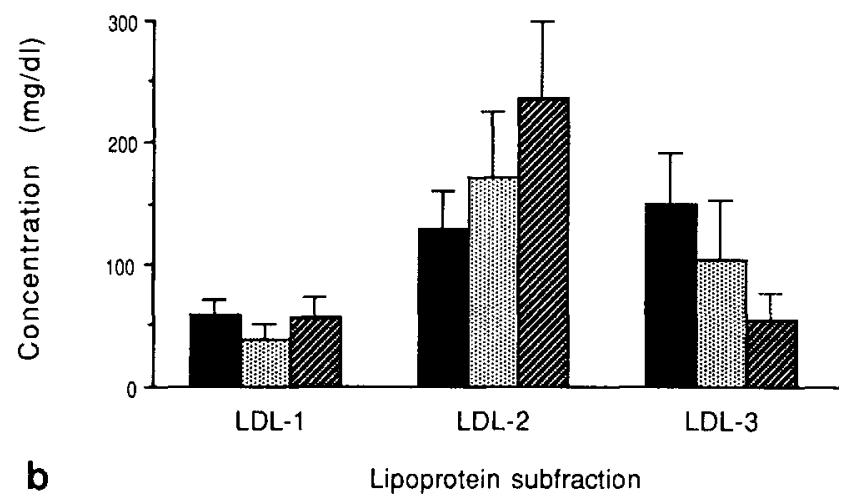

Fig. 2a,b. Plasma concentrations (computed as described in Fig. 1) of VLDL (a) and LDL (b) subfractions isolated by cumulative flotation ultracentrifugation. Statistical analyses. a Comparisons of pretreatment subfractions vs post-treatment and control subfractions respectively: VLDL 1 and $2, p<0.001$ vs both; VLDL- $3 ; p<0.001$ vs pre-treatment, $p<0.01$ vs controls: comparisons of post-treatment values to controls; VLDL-1, not significant; VLDL-2, $p<0.005$; VLDL-3, $p<0.02$. b Comparisons of pre-treatment subfractions to post-treatment and control subfractions respectively: LDL-1, $p<0.001$ and not significant; LDL-2, $p<0.05$ and $p<0.001 ; \mathrm{LDL}-3$, $p<0.005$ and $p<0.001$ : comparisons of post-treatment values to controls: LDL-1, $p<0.02$; LDL-2, $p<0.05$; LDL-3, $p<0.02$. Pretreatment; post-treatment; control

triglycerides as compared to control fractions. In contrast, VLDL-3 appeared to be triglyceride-enriched, but poorer in esterified cholesterol and, to a lesser extent, free cholesterol. On the whole, however, differences were far less extensive than those observed for absolute concentrations of the VLDL components.

The protein component of the subfractions was examined in broad terms by fractionation into apo B (tetramethyl urea insoluble) and non-apo B (tetramethyl urea soluble, essentially apos $C$ and $E$ ) proteins. A lower apo B/non-apo B protein ratio was observed in all subfractions from the diabetic groups (Table 4) although there was a large degree of variation between individuals. The differences were significant for VLDL-3.

\section{LDL subfractions}

There were striking differences in the LDL distribution profile of the pre-treatment diabetic patients as compared to the control subjects. Whereas LDL-2 was significantly lower than control values, LDL-3 was significantly in- 
Table 2. Concentrations of lipid and protein components of VLDL subfractions

\begin{tabular}{|c|c|c|c|c|c|c|c|c|c|}
\hline \multirow[t]{2}{*}{ Parameter } & \multicolumn{3}{|l|}{ VLDL1 } & \multicolumn{3}{|l|}{ VLDL 2} & \multicolumn{2}{|l|}{ VLDL 3} & \multirow[b]{2}{*}{ Control } \\
\hline & Before & After & Control & Before & After & Control & Before & After & \\
\hline Protein & $8.5 \pm 4.0^{c}$ & $3.4 \pm 1.9^{f}$ & $1.5 \pm 1.0^{\mathrm{a}}$ & $11.0 \pm 3.7^{\circ}$ & $6.2 \pm 3.6^{\mathrm{e}}$ & $2.0 \pm 1.0^{\mathrm{a}}$ & $13.7 \pm 4.4$ & $11.4 \pm 3.7^{\circ}$ & $6.7 \pm 3.4^{8}$ \\
\hline $\mathrm{TG}$ & $80.9 \pm 36.7^{c}$ & $28.5 \pm 21.4$ & $16.1 \pm 8.1^{\mathrm{a}}$ & $63.8 \pm 20.6^{c}$ & $32.2 \pm 16.2^{\mathrm{e}}$ & $12.4 \pm 6.0^{\mathrm{a}}$ & $47.0 \pm 12.5^{\mathrm{d}}$ & $35.1 \pm 10.2^{e}$ & $19.8 \pm 18.3^{\mathrm{a}}$ \\
\hline $\mathrm{FC}$ & $4.2 \pm 2.3^{c}$ & $1.5 \pm 1.3$ & $0.7 \pm 0.3^{a}$ & $5.6 \pm 1.9^{\circ}$ & $2.5 \pm 1.6^{\mathrm{e}}$ & $0.7 \pm 0.4^{\mathrm{a}}$ & $7.5 \pm 2.3^{\mathrm{d}}$ & $5.6 \pm 2.0^{f}$ & $3.8 \pm 1.9^{a}$ \\
\hline $\mathrm{EC}$ & $5.8 \pm 3.5^{c}$ & $2.1 \pm 2.7$ & $0.9 \pm 0.9^{\mathrm{a}}$ & $10.4 \pm 4.5^{\circ}$ & $4.5 \pm 4.1^{f}$ & $1.2 \pm 1.1^{\mathrm{a}}$ & $18.1 \pm 6.1^{\mathrm{d}}$ & $12.0 \pm 4.9$ & $10.2 \pm 6.7^{b}$ \\
\hline
\end{tabular}

Average concentrations $(\mathrm{mg} / \mathrm{dl} \pm \mathrm{SD}$ ) of individual lipid and protein components of VLDL subfractions from diabetic $(n=10)$ and control $(n=10)$ subjects. Before, at entry; after, post-treatment. TG, triglycerides, PL, phospholipids, FC, free cholesterol, EC, esterified

${ }^{\mathrm{a}} p<0.001 ;{ }^{\mathrm{b}} p<0.05$ for pre-treatment vs control; ${ }^{\circ} p<0.005$;

d $p<0.05$ for pre-treatment vs post-treatment; e $p<0.005$;

${ }^{\mathrm{f}} p<0.05$ for post-treatment vs control cholesterol.

Table 3. Composition of VLDL subfractions

\begin{tabular}{|c|c|c|c|c|c|c|c|c|c|}
\hline \multirow[t]{2}{*}{ Parameter } & \multicolumn{3}{|l|}{ VLDL1 } & \multicolumn{3}{|l|}{ VLDL 2} & \multicolumn{3}{|l|}{ VLDL 3} \\
\hline & Before & After & Control & Before & After & Control & Before & After & Control \\
\hline Protein & $7.3 \pm 0.7$ & $8.8 \pm 2.1^{f}$ & $6.6 \pm 2.1$ & $10.0 \pm 1.0$ & $11.4 \pm 1.7$ & $9.9 \pm 1.7$ & $12.6 \pm 1.5^{\mathrm{d}}$ & $14.2 \pm 0.8$ & $14.1 \pm 1.2^{b}$ \\
\hline TG & $69.5 \pm 2.7$ & $69.7 \pm 4.0^{f}$ & $73.5 \pm 3.0^{\mathrm{b}}$ & $58.0 \pm 2.1^{d}$ & $60.0 \pm 4.7^{\mathrm{e}}$ & $66.0 \pm 3.7^{\mathrm{a}}$ & $43.8 \pm 2.4$ & $44.2 \pm 2.7$ & $40.7 \pm 5.1^{b}$ \\
\hline $\mathrm{PL}$ & $14.7 \pm 0.8$ & $14.4 \pm 1.0^{\circ}$ & $12.5 \pm 1.1^{a}$ & $17.5 \pm 0.7^{\mathrm{d}}$ & $16.9 \pm 0.8^{\mathrm{e}}$ & $15.5 \pm 0.7^{\mathrm{a}}$ & $20.0 \pm 0.7$ & $20.1 \pm 0.8^{\mathrm{f}}$ & $18.9 \pm 1.2$ \\
\hline $\mathrm{FC}$ & $3.7 \pm 0.9$ & $3.3 \pm 1.5$ & $3.3 \pm 0.9$ & $5.2 \pm 1.0$ & $4.6 \pm 1.4^{\mathrm{E}}$ & $3.2 \pm 0.6^{\mathrm{a}}$ & $7.0 \pm 0.9$ & $6.9 \pm 0.6$ & $7.7 \pm 1.0$ \\
\hline $\mathrm{EC}$ & $4.9 \pm 1.7$ & $3.9 \pm 2.2$ & $3.9 \pm 3.0$ & $9.2 \pm 1.5^{\mathrm{d}}$ & $7.2 \pm 2.8$ & $5.3 \pm 3.0^{\mathrm{a}}$ & $16.6 \pm 1.9^{c}$ & $14.7 \pm 1.9$ & $18.5 \pm 5.6$ \\
\hline
\end{tabular}

Compositions are expressed as relative concentrations $(\mathrm{g} / 100 \mathrm{~g} \pm \mathrm{SD})$ of individual lipid and total protein components of VLDL subfractions from diabetic $(n=10)$ and control $(n=10)$ subjects. Before, at entry; after, post-treatment. TG, triglycerides, PL, phospholipids, FC, free cholesterol, EC, esterified cholesterol.

${ }^{\mathrm{a}} p<0.001 ;{ }^{\mathrm{b}} p<0.05$ for pre-treatment vs control; ${ }^{\mathrm{c}} p<0.005$;

d $p<0.05$ for pre-treatment vs post-treatment; e $p<0.005$;

f $p<0.05$ for post-treatment vs control

creased (Fig. 2 b). In contrast, LDL-1 was present in similar concentrations in the pre-treatment diabetic patients and control subjects. Treatment was accompanied by important modifications to this lipoprotein distribution profile. Thus, LDL-3 (and LDL-1) were reduced in concentration, whilst higher levels of LDL-2 were observed (Fig. 2 b). All changes were statistically significant. Differences between pre-treatment diabetic and control subjects with respect to the concentrations of the individual components of the subfractions (Table 5) mirrored differences in overall plasma concentrations of each subfraction. Moreover, treatment appeared to induce parallel modifications to concentrations of all components of a particular subfraction. As a result, there were no gross differences in the relative compositions of the subfractions from either diabetic or control groups (Table 6). There was, however, a tendency for LDL1 and 2 to be enriched in triglycerides and somewhat depleted in free cholesterol.

As with the VLDL subfractions, LDL-1 had a significantly lower ratio of apo B/non-apo B protein in both diabetic groups (Table 4).

\section{Discussion}

This study provides the first detailed analysis of lipoprotein subfractions spanning the VLDL/LDL metabolic cascade in Type 2 diabetic patients. It highlights modifications to the lipoprotein profile of poorly-controlled diabetic patients and indicates the potential of even shortterm therapy to correct these changes. Finally, it under- lines abnormalities of the LDL distribution profile, abnormalities not apparent from measurements of the total or LDL cholesterol levels.

Attention is being increasingly focussed on the metabolic complexity and attendant structural diversity of VLDL and LDL. It should help define the atherogenic potential of lipoprotein subfractions and clarify the pathological consequences of modifications to the VLDL/LDL metabolic cascade. Some tentative conclusions have already emerged. Thus, large VLDL (subfractions 1 and 2) do not appear to be atherogenic per se; their diametres hinder penetration of the blood vessel wall, limiting their accumulation and contribution to developing atherosclerotic lesions [20]. Neither are they quantitatively converted to the principal atherogenic lipoprotein species, LDL. Studies in non-diabetic populations have shown that, after being processed to the VLDL-3 range, a substantial proportion is directly removed from the plasma $[4$, $5,13]$ : this would also appear to be the situation in diabetic patients [21]. They do, however, give rise to lipoproteins of intermediate density (IDL, straddling the VLDL-3/LDL1 density spectrum) which are particularly atherogenic lipoprotein species $[10,22,23]$. A direct correlation between levels of large VLDL and IDL has been demonstrated in diabetic patients [24]. VLDL -3 is a particularly complex density region as it encompasses catabolic remnants derived from triglyceride-rich lipoprotein metabolism and newly synthesised small VLDL destined for quantitative transformation to LDL. As mentioned above, it is a particularly atherogenic lipoprotein subfraction, probably due to the presence of catabolic remnants. 
Table 4. Ratio of apo B to non-apo B apolipoproteins in lipoprotein subfractions

\begin{tabular}{lllll}
\hline \multirow{2}{*}{$\begin{array}{l}\text { Diabetic } \\
\text { group }\end{array}$} & \multicolumn{4}{l}{ Ratio (apo B/non-apo B) } \\
\cline { 2 - 5 } & VLDL1 & VLDL2 & VLDL3 & LDL1 \\
\hline Before & $0.68 \pm 0.41$ & $0.95 \pm 0.38$ & $1.70 \pm 0.50$ & $10.70 \pm 8.80$ \\
After & $0.83 \pm 0.67$ & $0.95 \pm 0.40$ & $1.90 \pm 0.4$ & $10.40 \pm 9.40$ \\
Control & $0.91 \pm 0.61$ & $1.15 \pm 0.79$ & $3.80 \pm 2.70^{\mathrm{a}}$ & $27.80 \pm 17.30^{\mathrm{a}}$ \\
\hline
\end{tabular}

Subfractionation was achieved by treatment of lipoprotein fractions with tetramethyl urea. The protein content of precipitable (apo B) and non-precipitable (non-apo B apolipoproteins) material was quantified [17] and the above values are the ratios $( \pm S D)$ of these measurements $(n=10)$.

${ }^{a} p<0.05$ vs both diabetic groups

Judging from its predominance in control subjects, LDL-2 can be considered to represent the normal form of LDL, and is thus the preferred substrate for the LDL receptor. In contrast, small, dense LDL (LDL-3) shows strong associations with cardiovascular disease in nondiabetic subjects $[25,26]$ suggesting a particularly atherogenic form of LDL. This may be a consequence of its smaller size facilitating penetration of the blood vessel wall. In addition, due to its high protein content, apo B may be more visible and thus more accessible for binding by the vessel wall matrix.

In the light of these considerations, poorly-controlled diabetic patients show an indisputable atherogenic lipoprotein profile. Firstly, VLDL-3 concentrations are increased, no doubt consequent to increased VLDL-1 and 2. This agrees with previous reports of increased IDLin poorly-controlled diabetic patients [24, 27-29]. Secondly, and more strikingly, the LDL distribution profile is completely awry. Notably, concentrations of LDL-2 are decreased, and those of LDL-3 are increased. This could be the basis of LDL polydispersity previously noted in diabetic subjects [30]. These anomalies would not be suspected from measurements of total cholesterol or even LDL-cholesterol levels, as there were no significant differences between pretreatment patients and control subjects. The exact causes of the modified LDL distribution, particularly increases in small, dense LDL in hypertriglyceridaemia, are not clear. One possibility is that they arise directly from the remodelling of certain VLDL subfractions, and are genetically determined $[31,32]$. Other likely candidates are the lipid transfer proteins [33-35]. Hypertriglyceridaemia would lead to exaggerated transfer of triglycerides into LDL. Their subsequent hydrolysis, probably by hepatic lipase [36], yields smaller, denser LDL particles, as observed in the poorly-controlled diabetic patients. Further studies will be necessary to establish whether hypertriglyceridaemia is sufficient to provoke the modifications of the LDL profile, as appears to be the case in non-diabetic populations [34], or whether features specific to the diabetic condition also play a role. The question merits particular attention as presently there is no basisfor presuming that the secondary hypertriglyceridaemia of the diabetic patients is metabolically equivalent to the primary hypertriglyceridaemia of non-diabetic populations. Moreover, primary hypertriglyceridaemia is a notoriously heterogeneous, poorly understood disorder for which raised triglyceride levels are a blanket description.

Although the question was not fully addressed, this study underlines that even short-term therapy seeking pri-

Table 5. Concentrations of lipid and protein components of LDL subfractions

\begin{tabular}{|c|c|c|c|c|c|c|c|c|c|}
\hline \multirow[t]{2}{*}{ Parameter } & \multicolumn{3}{|l|}{ LDL1 } & \multicolumn{3}{|l|}{ LDL2 } & \multicolumn{3}{|l|}{ LDL3 } \\
\hline & Before & After & Control & Before & After & Control & Before & After & Control \\
\hline Protein & $10.8 \pm 2.4^{c}$ & $7.0 \pm 2.5^{\mathrm{d}}$ & $11.1 \pm 3.0$ & $30.6 \pm 7.1$ & $38.5 \pm 13.1^{f}$ & $54.4 \pm 18.5^{a}$ & $41.0 \pm 11.6^{\mathrm{d}}$ & $27.1 \pm 12.7^{e}$ & $13.9 \pm 5.9^{a}$ \\
\hline TG & $7.2 \pm 3.0^{\mathrm{d}}$ & $5.4 \pm 1.6$ & $6.4 \pm 2.4$ & $7.9 \pm 3.1$ & $9.7 \pm 2.4$ & $11.2 \pm 2.9^{\mathrm{b}}$ & $6.0 \pm 2.6$ & $4.7 \pm 1.7^{\mathrm{e}}$ & $2.4 \pm 1.1^{a}$ \\
\hline $\mathrm{FC}$ & $6.2 \pm 4.0$ & $3.5 \pm 1.5^{\mathrm{e}}$ & $5.7 \pm 1.6$ & $10.7 \pm 3.1^{\mathrm{d}}$ & $14.8 \pm 4.8^{e}$ & $22.6 \pm 5.8^{\mathrm{a}}$ & $10.9 \pm 3.6^{\mathrm{d}}$ & $7.9 \pm 3.9^{\mathrm{e}}$ & $4.4 \pm 1.8^{\mathrm{a}}$ \\
\hline $\mathrm{EC}$ & $22.6 \pm 5.7^{c}$ & $14.1 \pm 4.9^{f}$ & $21.0 \pm 6.9$ & $53.3 \pm 14.8^{\mathrm{d}}$ & $70.5 \pm 24.0^{f}$ & $100.0 \pm 26.2^{\mathrm{a}}$ & $61.0 \pm 18.4^{c}$ & $42.6 \pm 21.5^{\mathrm{f}}$ & $23.2 \pm 9.7^{\mathrm{a}}$ \\
\hline
\end{tabular}

Average concentrations $(\mathrm{mg} / \mathrm{dl} \pm \mathrm{SD}$ ) of individual lipid and protein components of LDL subfractions from diabetic $(n=10)$ and control $(n=10)$ subjects. Before, at entry; after, post-treatment. TG, triglycerides, PL, phospholipids, FC, free cholesterol, EC, esterified cho-

${ }^{\mathrm{a}} p<0.001 ;{ }^{\mathrm{b}} p<0.05$ for pre-treatment vs control; ${ }^{\mathrm{c}} p<0.005$;

d $p<0.05$ for pre-treatment vs post-treatment; e $p<0.005$;

f $p<0.05$ for post-treatment vs control lesterol.

Table 6. Composition of LDL subfractions

\begin{tabular}{|c|c|c|c|c|c|c|c|c|c|}
\hline \multirow[t]{2}{*}{ Parameter } & \multicolumn{3}{|l|}{ LDL1 } & \multicolumn{3}{|l|}{ LDL2 } & \multicolumn{3}{|l|}{ LDL3 } \\
\hline & Before & After & Control & Before & After & Control & Before & After & Control \\
\hline Protein & $18.5 \pm 2.0$ & $18.2 \pm 2.0$ & $19.7 \pm 1.7$ & $23.8 \pm 2.8$ & $22.4 \pm 2.4$ & $22.7 \pm 2.7$ & $27.7 \pm 3.5$ & $26.4 \pm 2.6$ & $25.6 \pm 3.0$ \\
\hline $\mathrm{TG}$ & $12.1 \pm 3.6^{\mathrm{d}}$ & $14.4 \pm 3.0^{f}$ & $11.5 \pm 2.8$ & $6.0 \pm 1.5$ & $5.9 \pm 1.3$ & $4.8 \pm 1.1^{b}$ & $4.0 \pm 0.9$ & $4.8 \pm 1.0$ & $4.3 \pm 0.7$ \\
\hline PL & $21.9 \pm 1.6$ & $22.3 \pm 1.8$ & $21.7 \pm 0.9$ & $20.9 \pm 1.7$ & $22.0 \pm 1.7^{f}$ & $20.6 \pm 1.0$ & $19.8 \pm 1.4$ & $20.4 \pm 1.1$ & $19.9 \pm 1.0$ \\
\hline $\mathrm{FC}$ & $8.8 \pm 2.4$ & $9.0 \pm 1.7$ & $10.2 \pm 0.9$ & $8.3 \pm 1.5$ & $8.7 \pm 0.9^{f}$ & $9.6 \pm 0.6^{\mathrm{b}}$ & $7.3 \pm 1.3$ & $7.8 \pm 1.1$ & $8.1 \pm 1.0$ \\
\hline $\mathrm{EC}$ & $38.6 \pm 5.3$ & $36.0 \pm 4.5$ & $37.0 \pm 5.2$ & $40.9 \pm 2.9$ & $41.1 \pm 3.6$ & $42.2 \pm 2.0$ & $41.1 \pm 2.3$ & $40.6 \pm 2.6$ & $42.0 \pm 2.4$ \\
\hline
\end{tabular}

Compositions are expressed as relative concentrations $(\mathrm{g} / 100 \mathrm{~g} \pm \mathrm{SD})$ of individual lipid and protein components of LDL subfractions from diabetic $(n=10)$ and control $(n=10)$ subjects. Before, at entry; after, post-treatment. TG, tri- glycerides, PL, phospholipids, FC, free cholesterol, EC, esterified cholesterol.

${ }^{b} p<0.05$ for pre-treatment vs control; ${ }^{d} p<0.05$ for pre-treatment vs post-treatment; ${ }^{\mathrm{f}} p<0.05$ for post-treatment vs control 
marily an improvement of glycaemic control has an evident beneficial influence on the lipoprotein profile. All three VLDL subfraction concentrations were significantly reduced. Within the LDL density spectrum, there was a net tendency to normalise the profile with significant changes in the levels of LDL-2 and LDL-3. It is probable that a longer period of improved metabolic control would have more fully corrected the lipoprotein anomalies [37]. In this context, weight loss will also undoubtedly contribute to these improvements as obesity has recently been reported to modify independently plasma lipids/lipoproteins in diabetic subjects [38]. Whilst the patients involved in this study were obese, all manifested dramatically improved lipoprotein profiles, whether or not weight loss occurred. Thus, it is doubtful that obesity played a major role in these patients. The considerations also raise the question of whether particular treatment regimens are more efficient in correcting lipid anomalies. No conclusions can be drawn from the present study; there were, however, no apparent major differences in the response of insulintreated, as opposed to non-insulin-treated patients, albeit during a short period of therapy. Moreover, Denke and Grundy [39] have suggested that, providing good glycaemic control is achieved, insulin or oral anti-diabetic therapy have equally effective lipid lowering capacities. Dietary habits were modified during hospitalisation and certainly contributed to improved glycaemic control. Their influence on the lipoprotein profile is less clear. It is difficult to conceive of dietary composition playing a major role. Prior to entry, it was similar to that of the Geneva population with a higher fat content than during hospitalisation; fats do not modify plasma triglyceride levels [40]. Indeed, the dietary changes implemented (lower fat, higher carbohydrate) would, if anything, tend to raise triglyceride levels [41] and accordingly counteract the observed improvements of the lipoprotein profile. Thus, any role played by dietary modifications was probably via reduced caloric intake [40], although it was not significant for this small group of patients.

Another feature examined in this study was lipoprotein composition. There is considerable disagreement as to whether, and what, compositional modifications occur in Type 2 diabetic subjects $[1-3,42,43]$. Some significant differences between diabetic and control groups were observed. These tended to agree with previous observations; increased triglyceride/apo B ratios in VLDL ([2]; we show that it extends to the VLDL subfractions) and a tendency for LDL to be enriched in triglycerides [6]. On the whole, however, differences in lipoprotein subfraction compositions were less marked than differences in concentrations. It is possible that this reflects subtle modifications of lipoprotein composition which can only be revealed by examining larger populations. However, we believe that it raises a more important consideration. Previous studies have essentially examined whole VLDL and LDL, not subfractions [2]. Thus, reported compositional anomalies may have been due in part to the relative contributions of different lipoprotein subfractions of essentially normal composition.

The above considerations apply to the composition of lipids and total protein. A closer examination of the apoli- poprotein components suggests potentially important modifications in diabetic patients. Albeit subjected to limited fractionation, the results indicate enrichment of non-apo B apolipoproteins (apos C and E) in VLDL-3 and LDL-1. These observations extend previous suggestions of a modified apolipoprotein content of diabetic VLDL [27,44], although Stalenhoef et al. [45] were unable to confirm this for the apos $\mathrm{C}$. We did not examine the relative concentrations of apos $\mathrm{C}$ and $\mathrm{E}$, but in a previous study we observed an increased apo C:apo $\mathrm{E}$ ratio in Type 2 diabetic patients [19]. As apos $C$ and $E$ greatly influence metabolism of VLDL/IDL, these observations could have important implications. A direct consequence of these modifications could be the accumulation of VLDL-3 if the receptor binding capacity of apo $\mathrm{E}$ is compromised.

To conclude, a modified, apparently atherogenic lipoprotein distribution was the major feature of the poorlycontrolled diabetic patients partaking in this study. Such modifications may have been expected for the VLDL subfractions, given the pre-treatment hypertriglyceridaemia, but not for the LDL subfractions, if considering plasma cholesterol levels alone. The profile responded relatively rapidly to improved metabolic control. Taken together with recent epidemiological data [46] implicating hypertriglyceridaemia as a particular risk factor in diabetes, the results suggest that strict control of plasma triglycerides should also be a primary concern in diabetic patients.

Acknowledgements. The technical expertise of M-C.Brulhart and F. Ruinard are gratefully acknowledged. The authors express their gratitude to Prof. J-P. Assal and the personnel of the Diabetes Teaching Unit at the University Hospital in Geneva. The work was supported by grants from the Fonds national de la recherche scientifique (No 3.852.088), the Fondation Suisse de Diabète and the Société Académique de Genève.

\section{References}

1. Gibbons GF (1986) Hyperlipidaemia of diabetes. Clin Sci 71: $477-486$

2. Howard BV (1987) Lipoprotein metabolism in diabetes. J Lipid Res 28: 613-628

3. Betteridge DJ (1989) Lipids, diabetes, and vascular disease: the time to act. Diabetic Med 6: 195-218

4. Reardon MF, Fidge NH, Nestel PJ (1978) Catabolism of very low density lipoprotein in man. J Clin Invest 61: 850-860

5. Janus ED, Nicoll A, Wootton R, Turner PR, Magill PJ, Lewis B (1981) Quantitative studies of very low density lipoprotein conversion to low density lipoprotein in normal controls and primary hyperlipidaemic states and the role of direct secretion of low density lipoprotein in heterozygous familial hypercholesterolaemia. Eur J Clin Invest 10: 149-160

6. Nikkila EA (1984) HDL in relation to the metabolism of triglyceride-rich lipoproteins. In: Miller NE, Miller GJ (eds) Clinical and metabolic aspects of high density lipoproteins. Elsevier, Amsterdam, pp 217-274

7. Reichl D, Miller NE (1989) Pathophysiology of reverse cholesterol transport. Insights from inherited disorders of lipoprotein metabolism. Arteriosclerosis 9: 785-797

8. Austin MA (1989) Plasma triglyceride as a risk factor for coronary heart disease. The epidemiologic evidence and beyond. Am J Epidemiol 129: 249-259

9. Castelli WP (1986) The triglyceride issue: a view from Framingham. Am Heart J 112: 432-437 
10. Study group, European Atherosclerosis Society (1988) The recognition and management of hyperlipidaemia in adults: a policy statement of the European Atherosclerosis Society. Eur Heart J 9: $571-600$

11. Fisher WR, Zech LA, Bardalage P, Warmke G, Berman M (1980) The metabolism of apolipoprotein B in subjects with hypertriglyceridaemia and polydisperse LDL. J Lipid Res 21: 760-774

12. Packard CJ, Shepherd J, Joerns S, Gotto AMJr, Taunton OD (1979) Very low density and low density lipoprotein subfractions in type III and type IV hyperlipoproteinaemia. Chemical and physical properties. Biochem Biophys Acta 572: 269-282

13. Packard CJ, Munro A, Lorimer AR, Gotto AMJr, Shepherd J (1984) Metabolism of apolipoprotein B in large triglyceride-rich very low density lipoproteins of normal and hypertriglyceridemic subjects. J Clin Invest 74:2178-2192

14. Lindgren FT, Jensen LC, Hatch FT (1972) The isolation and quantitative analysis of serum lipoproteins. In: Nelson GJ (ed) Blood lipids and lipoproteins. Quantitation, composition and metabolism. Wiley Interscience, New York, pp 182-274

15. James RW, Pometta D (1990) Differences in lipoprotein subfraction composition and distribution between type 1 diabetic men and control subjects. Diabetes 39: 1158-1164

16. James RW, Pometta D (1990) Immunofractionation of high density lipoprotein subclasses 2 and 3 . Similarities and differences of fractions isolated from male and female populations. Atherosclerosis $83: 35-45$

17. Lowry OH, Rosebrough NJ, Farr AL, Randall PJ (1951) Protein measurement with the Folin phenol reagent. J Biol Chem 193: 265-275

18. Kane JP, Sata T, Hamilton RL, Havel RJ (1975) Apoprotein composition of very low density lipoproteins of human serum. $\mathbf{J}$ Clin Invest 56: 1622-1634

19. Leowsky J, James RW, Taton J, Pometta D (1988) The influence of metabolic control on very low density lipoprotein composition in hypertriglyceridaemic type II diabetics. A study using heparin-sepharose chromatography. Metabolism 37: 721-726

20. Stender S, Zilversmit DB (1981) Transfer of plasma lipoprotein components and of plasma proteins into aortas of cholesterol-fed rabbits: molecular size as a determinant of plasma lipoprotein influx. Arteriosclerosis 1: 38-49

21. Howard BV, Abbott WGH, Beltz WF, Harper IT, Fields RM, Grundy SM, Taskinen M-R (1987) Integrated study of low density lipoprotein metabolism and very low density lipoprotein metabolism in non-insulin-dependent diabetes. Metabolism 36: $870-877$

22. Brewer HB (1983) Type III hyperlipoproteinemia: diagnosis, molecular defects, pathology, and treatment. Ann Int Med 98: 623-664

23. Krauss RM, Lindgren FT, Williams PT, Kelsey SF, Brensike J, Vranizan K, Detre KM, Levy RI (1987) Intermediate density lipoproteins and coronary heart disease progression in hypercholesterolaemic men. Lancet II: $62-66$

24. Yoshino G, Kazumi T, Iwai M, Matsuba K, Iwatani I, Matsushita M, Kasama T, Baba S (1988) Recommendations for strict control of plasma triglycerides in diabetic subjects. Diabetes Care 11:794-795

25. Musliner TA, Krauss RM (1988) Lipoprotein subspecies and risk of coronary disease. Clin Chem 34 : B 78-B 83

26. Austin MA, Breslow JL, Hennekens CH, Buring JE, Willett WC, Krauss RM (1988) Low density lipoprotein subclass patterns and risk of myocardial infarction. JAMA 260: 19171921

27. Weisweiler $P$, Schwandt $P$ (1987) Type I (insulin-dependent) versus type 2 (non-insulin dependent) diabetes mellitus: characterisation of serum lipoprotein alterations. Eur J Clin Invest 17: $87-91$

28. Joven J, Vilella E, Costa B, Turner PR, Richart C, Masana L (1989) Concentrations of lipids and apolipoproteins in patients with clinically well controlled insulin dependent and non-insulin dependent diabetes. Clin Chem 35:813-816
29. Kasama T, Yoshino G, Iwatani I, Iwai M, Hatakana H, Kazumi T, Oimomi M, Baba S (1987) Increased cholesterol concentration in intermediate density lipoprotein fraction of normolipidaemic non-insulin-dependent diabetes. Atherosclerosis 63 : 263-266

30. Fisher W (1983) Heterogeneity of plasma low density lipoproteins: manifestations of the physiologic phenomenon in man. Metabolism 32: 283-291

31. Austin MA, Krauss RM (1986) Genetic control of low density lipoprotein subclasses. Lancet II: 592-595

32. Austin MA, King M-C, Vranizan KM, Newman B, Krauss RM (1988) Inheritance of low-density lipoprotein subclass patterns: results of complex segregation analysis. Am J Hum Genet 43: 838-846

33. Tall A (1986) Plasma lipid transfer proteins. J Lipid Res 27: 361 367

34. Deckelbaum RJ, GranotE, Oschry Y, Rose L, Eisenberg S (1984) Plasma triglyceride determines structure-composition in low and high density lipoproteins. Arteriosclerosis 4: 225-231

35. Bagdade JD, Buchanan WE, Kuusi T, Taskinen M-R (1990) Persistent abnormalities in lipoprotein composition in noninsulin-dependent diabetes after intensive insulin therapy. Arteriosclerosis 10: 232-239

36. Demant T, Carlson LA, Holmquist L, Karpe F, Nilsson-Ehle P, Packard CJ, Shepherd J (1988) Lipoprotein metabolism in hepatic lipase deficiency: studies on the turnover of apolipoprotein $B$ and on the effect of hepatic lipase on high density lipoprotein. J Lipid Res 29: 1603-1611

37. Rivellese A, Riccardi G, Romano G, Giacco R, Patti L, Marotta G, Annuzzi G, Mancini M (1988) Presence of very low density lipoprotein compositional abnormalities in Type 1 (insulin-dependent) diabetic patients; effects of blood glucose optimisation. Diabetologia 31: 884-888

38. Laakso M, Pyörälä K (1990) Adverse effects of obesity on lipid and lipoprotein levels in insulin dependent and non-insulin dependent diabetes. Metabolism 39:117-122

39. Denke MA, Grundy SM (1989) Treatment of diabetic dyslipidaemia. Biochem Soc Trans 17:56-58

40. Grundy SM, Denke MA (1990) Dietary influence on serum lipids and lipoproteins. J Lipid Res 31: 1149-1172

41. Mancini M, Mattock M, Rabaya E, Chait A, Lewis B (1973) Studies of the mechanisms of carbohydrate-induced lipaemia in normal man. Atherosclerosis 17: 445-454

42. Ishibashi S, Yamada N, Shimano H, Takaku F, Akanuma Y, Murase $\mathrm{T}$ (1989) Composition of very low density lipoproteins in non-insulin dependent diabetes mellitus. Clin Chem 35: 808-812

43. Billingham MS, Milles JJ, Bailey CJ, Hall RA (1989) Lipoprotein subfraction composition in non-insulin dependent diabetes treated by diet, sulphonylurea, and insulin. Metabolism 38: 850 857

44. Gabor J, Spain M, Kalant N (1980) Composition of serum verylow-density and high-density lipoproteins in diabetes. Clin Chem 2: $1261-1265$

45. Stalenhoef AFH, Demacker PNM, Lutterman JA, Van't Laar A (1982) Apolipoprotein C in Type 2 (non-insulin-dependent) diabetic patients with hypertriglyceridaemia. Diabetologia 22: 489-491

46. Fontbonne A, Eschwège E, Cambien Fet al. (1989) Hypertriglyceridaemia as a risk factor of coronary heart disease mortality in subjects with impaired glucose tolerance or diabetes. Diabetologia 32: 300-304

Received: 17 July 1990

and in revised form: 22 October 1990

Dr. R. W.James

Division de Diabétologie

Département de Médecine

Hôpital Cantonal

CH-1211 Geneva 4

Switzerland 